\section{Aging and Depression: Studies on Rural Populations in Bulgaria during Communist and Post Communist Period}

\author{
Ignat C Petrov ${ }^{1 *}$ and Peter G Coleman ${ }^{2}$ \\ ${ }^{1}$ Clinical Centre of Endocrinology and Gerontology, Medical University Sofia, \\ Bulgaria \\ ${ }^{2}$ School of Psychology, University of Southampton, England, UK
}

\begin{abstract}
Purpose: The mental health of older people from the Bulgarian rural population has been studied at two different historical periods.

Sample and methods: Between 1971 and 1984 a comprehensive cross-sectional and longitudinal investigation on the mental health of people of 70 years and over, representing $20 \%$ random sample of the population in that age group of 46 villages near Sofia, was carried out. In that study, we used an interview, 9 psychometric (cognitive and psycho-motor) tests and the Self-Evaluation Test (SET) which involved respondents situating themselves on scales represented by vertical lines. In 2007 a sample of 80 persons of 60 years and over were interviewed at two of the same Bulgarian villages. In 2008 the same older persons, from the two villages, were studied again using three depressive scales (HAD-D of Zigmond and Snaith, the Geriatric depression scale of Yesavage et al. and the Zung self-rating depressive scale) as well as SET.
\end{abstract}

Results and discussion: A high level of depression, surpassing $50 \%$ in the age 60 and over, was confirmed in 2007 and 2008 on the elderly from the two Bulgarian villages. Depressive prevalence among Bulgarian people aged 70 and over in 2008 seemed to be higher and the self-evaluation of these people, especially their self-evaluation of health, was lower than it was in 1972. These differences might partly reflect social and cultural differences between the

*Corresponding author: Ignat C Petrov, Clinical Centre of Endocrinology and Gerontology, Medical University Sofia, Sofia, ul. Zdrave 2, Bulgaria, Tel: +359 888353937; E-mail: ignatpetrov@yahoo.com

Citation: Petrov IC, Coleman PG (2019) Aging and Depression: Studies on Rural Populations in Bulgaria during Communist and Post Communist Period. J Gerontol Geriatr Med 5: 037.

Received: October 03, 2019; Accepted: October 23, 2019; Published: October 30, 2019

Copyright: (C) 2019 Petrov IC and Coleman PG. This is an open-access article distributed under the terms of the Creative Commons Attribution License, which permits unrestricted use, distribution, and reproduction in any medium, provided the original author and source are credited. two historical periods. The results indicated close relations between depression and self-evaluation. The SET used is sensitive towards depressive symptoms; at the same time it has projective qualities giving information about personality values and motives of dissatisfaction. The leading motives of personal dissatisfaction, including lower self-evaluation on the scale of happiness of SET, according to the results of the 2008 study, proved to be ill health and financial difficulties, these motives being significantly more prevalent in 2008 than in 1972. We discuss whether the rapid social and economic changes in Bulgaria after 1990 may contribute to some psychogenic increase of the number of depressive states together with a lowering of the self-evaluation.

\section{Background}

Aging is a 'universal experience' since at the present time almost all individuals have the chance to reach old or very old age. Mental and somatic illnesses are common in late life: they both could develop independently of natural ageing, but in many cases these phenomena combine, overlap and aggravate one another. Dementias and depressions are among the commonest mental health problems in later life. The data on the prevalence of depressions in older age vary, but on the whole they are present in $10-15 \%$ or $15-20 \%$ of the people aged 65 and over [1,2]. At older ages the major depressions are not more prevalent than in middle age. The depressions with late onset are predominantly 'minor' and some parts of them seem to lie in the border area between characteristics common to aging and mental disorder.

Not only the incidence of (minor) depression, but also actual suicides increase with advancing age, especially among men. One part of old age suicides seem to be related with real life difficulties (e.g., loneliness in older men) and another part probably occurs as an outcome of major depression [3]. It is necessary to consider whether there is a phenomenal likeness between aging and depression or a causal pathogenic relationship. Natural aging itself resembles depression with some of its common characteristics: the retardation of reactions and behavior; the trends towards introversion of interests and mode of life; attitudes of increased incertitude, cautiousness and anxiety; some 'normal' decrease in feelings of joy; familiarization with thoughts of death [3]. The gradual drop in vitality, spontaneous activity and drive are also present in the course of the natural ageing of humans and animals. Social activities and interests also decline in humans despite their communal character. Behavior requiring physical and mental strain or competition decline as well as activities involving a broader extent of communication and contacts. Individual and quiet occupations within family life become more prevalent. As a result interests and activities do become more introverted and lose strength, swing, fight and strife [4]. Studying life satisfaction in different age groups, Traeldal, et al., calculated that the orientation toward personality compared to the orientation toward the environment could be 1:8 (between 18 and 29 years of age); 1: 4 (at 30-44 years); 1:2 (50-69 years) and 1:1 (over the age of 70 years), i.e., the trend towards introversion increases eight times with aging. 
Citation: Petrov IC, Coleman PG (2019) Aging and Depression: Studies on Rural Populations in Bulgaria during Communist and Post Communist Period. J Gerontol Geriatr Med 5: 037.

The lessening of spontaneous activity as well as the slowing of reactions are primary age-related changes. The trends towards incertitude, cautiousness, anxiousness, introversion and rigidity at older age are more complex in their origin. They also could be partly related with biological involution, including age decline in cognitive and psychomotor abilities. But at the same time they are influenced by adverse environmental factors e.g., the stereotypical undervaluation and rejection of the older people by younger people and society. The drop of vitality and of the adaptive capacities along with the trends toward incertitude and anxiousness contribute to an age change in value orientations with a concentration on vital themes of health, family and past life.

In a study on a representative sample of rural people aged 70 and over we found that the value orientations were focused on their own health, family relations in a narrow circle (children and spouse) and economic security. Their concepts of happiness and unhappiness expressed in many cases their need of help and family ties, the insecurity of the future, the increased dependence with age of the immediate surroundings with the ambivalent experience of (a) dissatisfaction with insufficient care and consideration on the part of the closest relatives and (b) worry to maintain the status achieved in the course of life - both in the family and in the sphere of economic security. The outline of the basic value orientation of older people helps to understand the trends of symptoms in the mental disorders arising in late life [5].

\section{Material, Methods and Analysis of Results}

The mental health of older people from the Bulgarian rural population has been studied at two different historical periods. Between 1971 and 1984 a comprehensive cross-sectional and longitudinal investigation on the rural people aged 70 and over, representing $20 \%$ random sample of the population in that age group, from 46 villages near Sofia was carried out. In that study, among others, we firstly used the first part of the Self-Evaluation Test (SET) which involved respondents situating themselves on scales represented by five vertical lines capturing their Self-Evaluation (SE) of happiness, health, mental capacity, character and perceived attitude of others [6,7]. The points chosen on the five vertical lines were classified into a scale of 7 ratings and subsequently compared with a number of variables including social situation, health status and personality $[5,6]$.

In 2007,80 persons of 60 years and over were interviewed at two of the same Bulgarian villages. The study also covered another 80 older people from one Romanian village of similar socioeconomic status [8]. Using the Hospital Anxiety and Depression-D scale (HAD-D) [9] a significantly higher level of depression in Bulgarian than in Romanian elderly people has been found (mean scores 12.0 versus 7.4 ). We were surprised by the extent of this difference. To investigate further the high level of depression found in the Bulgarian sample, we carried out in 2008 a follow-up investigation. It proved possible to trace and interview 58 people aged $61-88$ of the original Bulgarian sample. In addition to the HAD-D scale, we used also the Zung Self-Rating Depression Scale [10], the Geriatric Depression Scale - GDS [11] and SET [6,7]. In 2008 we used the full range of the SET scales which involved respondents situating themselves on 15 vertical lines capturing the self-evaluation (SE) of:

- health;

- intellectual capacity;
- character or quality of personality;

- perceived attitude of others to the person;

- Happiness

The first five scales or lines constitute the first, obligatory part of the Self-Evaluation Test. They deal with more general categories, the most general and sensitive of them being the notion of happiness. The next 10 vertical lines or questions have more specific meanings and represent the second, optional part of SET. They involve self-evaluation about:

- sight;

- hearing;

- prevailing mood;

- sense of calm;

- energy;

- family life

- economic or financial situation;

- profession, work;

- past life satisfaction;

- current life satisfaction;

The levels of depression among Bulgarians proved to be high in 2008 as well they were in 2007 (according to the HAD-D scale 10.8 vs.12.0) [8].

We then compared the depression scores from the three depression scales as well as the Self-Evaluation (SE) of 55 persons ( 38 females and 17 men) studied in 2007 and again in 2008. They were rural Bulgarians, with an age range of 61 to 88 years, living in two villages near to Sofia. The age distribution was as follows: 10 were $61-69 ; 34$ were $70-79 ; 11$ were aged $80-88$ years. The rates of depression found by the three depressive scales were concordant. The rates found with the SET also were similar.

Of the 55 persons interviewed in 2008 only 20 had scores below 8 points i.e., within the norm according the HAD-D scale. 35 persons $(63.6 \%)$ had signs of depression since their scores were 8 and over. Moderate and severe depression showed 25 persons (45.5\%) with scores of 11 and more points. According to the GDS 32 elderly persons $(59.3 \%)$ had probable depression with scores 5 and over and 16 persons $(29.6 \%)$ had very probable depression with scores of 10 and more. According to the Zung scale 38 persons (69.1\%) showed signs of depression with scores 50 and over and $23(41.8 \%)$ had 60 points and over i.e. moderate and heavy depression (Table 1).

\begin{tabular}{|l|c|c|c|}
\hline Instruments & Probable Depression & Very Probable Depression & N \\
\hline HAD-D & $\begin{array}{c}34(63.6 \%) \\
\text { score } 8 \text { and over }\end{array}$ & $\begin{array}{c}25(45.5 \%) \\
\text { score } 11 \text { and over }\end{array}$ & 55 \\
\hline GDS & $\begin{array}{c}32(59.3 \%) \text { score } 5 \\
\text { and over }\end{array}$ & $\begin{array}{c}16(29.6 \%) \\
\text { score } 10 \text { and over }\end{array}$ & 55 \\
\hline Zung self-rating scale & $\begin{array}{c}38(69.1) \\
\text { score } 50 \text { and over }\end{array}$ & $\begin{array}{c}24(43.6 \%) \\
\text { score } 60 \text { and over }\end{array}$ & 55 \\
\hline \multicolumn{2}{|r|}{ Table 1: Rates of depression according to three scales used in 2008.} \\
\hline
\end{tabular}


Citation: Petrov IC, Coleman PG (2019) Aging and Depression: Studies on Rural Populations in Bulgaria during Communist and Post Communist Period. J Gerontol Geriatr Med 5: 037.

It must be acknowledged that the high prevalence of depression found with the scales used might be slightly exaggerated due to "depressive" answers to such questions like "the feeling to be slowed down" in the HAD-D or the presence of constipation or disturbed sleep in the Zung scale. Such questions refer to "symptoms" which could be linked not only with depressive disorder, but with aging per se [3].

Nevertheless it can be concluded that within the small number of elderly people examined:

- The levels of depression found by the four instruments were considerably concordant. The three depressive scales show rates of probable depression around 34 to $69 \%$ and of very probable or severe depression in around 28 to $40 \%$ of the sample;

- The majority of people with depression were in the age of 70 and over (with a peak in the age 70-79) but depression was relatively less common in the age range 60-69;

- The rates of depression found in 2008 in these two Bulgarian villages were unexpectedly high;

As to the concordance between the depressive scales used, 35 elderly persons had a score 8 and over on HAD-D; 33 of them or almost all have at the same time scores of 50 and over on the Zung scale, and 27 or four fifths of the sample have also scores of 5 and more on the GDS.

\section{Discussion}

There were much higher rates of late life depression evident in Bulgarian villages than in a Romanian one studied. In 2007 the comparison between Romanian and Bulgarian elderly persons on the basis of the HAD-D scale revealed a significant difference in the level of depression (Romanian mean 7.3; Bulgarian mean 12.0) [8]. It is not possible to give a definitive explanation of this striking difference. Despite a common recent history of communist rule followed by a return of capitalism, a number of historical, social and cultural differences between the two countries could play a part. One possible protective factor that has been identified is religious belief and practice. This continues to be much higher in Romanian than Bulgarian society $[8,12]$.

There were consistent negative associations between self-evaluation rates and depression. Using in 2008 the two parts of the Self-Evaluation Test with 15 scales [7] we confirmed that low self-ratings could indicate depressive symptoms. Of the 55 persons considered $24(43.6 \%)$ have chosen positions on the scale of happiness below the middle of the vertical line. Calculating the sum of the positions below the middle on all 15 scales of the test we found 22 persons $(40.0 \%)$ having 6 or more low positions on different lines. So the findings from the SET are very close to the findings indicating the presence of moderate or severe depression from the three depressive scales, especially from the HAD-D scale (43.6\%), and Zung (41.8\%).

Our previous study of the 1970's was on 708 elderly representing $20 \%$ random sample of all population aged 70 and over from 46 villages near Sofia [5]. Two of the same villages, nowadays already part of Sofia city, were subject of our studies also in 2007 and 2008. The data on prevalence of depression in these studies are difficult to compare because of the differences in historical and social circumstances. Moreover in the 1970's study the appraisal of depressions was mostly clinical, and we found $22.2 \%$ mild or more pronounced depressions. Calculated for the population of the two discussed villages 11 from 50 elderly persons (22.0\%) were appraised to be affected by depressions. The cases of another 6 persons from the 1972 study have been thought then to lay in the border zone between normal ageing and depression $[5,13,14]$. It is well known from numerous studies that the depressive scales find higher prevalence of depressive symptoms than do studies based on clinical appraisal.

In the 1970's rural study we firstly used the SET and we found a significant correlation between the lower self-ratings and the presence of depression. The scale of happiness proved to be the most sensitive $\mathrm{p}<0.001$ ), followed by the scales of health, intellectual capacity and character $($ at $p<0.05)[5,7,15]$. In order to examine more closely the relations between depression and lower Self-Evaluation (SE) we compared two subgroups from the 55 elderly persons examined in 2008:

- 15 elderly persons with scores around the norm on the three depressive scales HAD-D, GDS and Zung Self Rating Depression Scale;

- 10 persons with moderate or severe depression according to the three scales i.e., with HAD-D $\geq 11$, as well GDS $\geq 10$ and Zung $\geq 60$;

- 4 women from the 15 elderly in the group (A) were widows, but all they lived with some of their children and/or grandchildren. No one lived alone. In the group (B) from 10 elderly 8 were widows or widowers and four of them lived lonely

- 9 persons from (A) had positive SE of happiness above the middle score vs. no one from (B), whereas the middle position on the scale of happiness was occupied by 6 persons from (A) vs. only one on from the group (B)

- Low SE with a position below the middle had no one from A, but 9 persons from (B)

- No one from (A), but 9 persons from (B) have chosen six and more positions below the middle rank along all scales

Regarding the motives of dissatisfaction shared along the SET:

- 8 from 10 persons in group B shared health problems vs. 6 from 15 in group A

- 6 from 10 persons within group B shared financial difficulties vs. 5 from 15 in group A

- 5 from 10 persons in group B shared problems in their families including death of a close person vs. 3 from 15 in group A. Three elderly shared they felt loneliness, all women and all from group B

- 4 from 10 persons in group B indicated that they felt themselves physically too weak vs. 1 person from group A

- 4 from 10 persons in the group B spontaneously shared complaints about their memory vs. 1 from group A

Remarkably, to the question related to the self-evaluation of happiness - "what is missing to be higher in happiness" - 4 persons from group A answered approximately that there was nothing needed, that they were fully satisfied with their lives. 
Citation: Petrov IC, Coleman PG (2019) Aging and Depression: Studies on Rural Populations in Bulgaria during Communist and Post Communist Period. J Gerontol Geriatr Med 5: 037.

Finally, in comparing self-ratings from the SET in 2008 and 1972, we also found statistically significant differences using chi-square test. In 1972 the first part of the test was performed by 228 rural elderly aged 70 years and over. Nearly half of them (106 persons or $46.5 \%$ ) had mostly positive SE of happiness and chose positions above the middle of the line. The very middle of the scale was chosen by $27.2 \%$. Definitely negative self-evaluation scores with positions below the middle of the line were chose by 60 (26.3\%). In 200844 from 55 persons were in the age group 70 and over. Of them $14(31.8 \%)$ had positive, $11(25.0 \%)$ mid and 19 persons (43.1\%) low SE positions of happiness. There is a trend to lower self-evaluation of happiness in 2008, but without statistical significance according chi-square $(\mathrm{p}>0.05)$ striking are the differences on the scale of health. In 1972 89 persons or $39.0 \%$ had positive, $28.1 \%$ mid and 75 elderly $(32.9 \%)$ mostly negative SE. In 2008 only 4 persons $(9.1 \%)$ had positive SE of health, $31.8 \%$ chose the middle, and the majority ( 30 persons or $68.2 \%)$ chose ratings below the middle of the line $(\mathrm{p}<0.001)$. These sharp differences might partly reflect social and cultural differences between the two historical periods. In 2008 elderly people living in the villages near Sofia had undoubtedly higher level of education and much wider information, including health information, than was possible in 1972. It is an open question whether the differences in self-evaluation reflect also a more pessimistic view on the contemporary post-communist-transition period in the history of the country [16].

The content analysis of leading themes of personal dissatisfaction shared verbally during the self-evaluation of happiness showed differences too. In $200850.0 \%$ of the elderly explaining "what was missing to being happier" noted health problems (vs. $22.4 \%$ in 1972) $(\mathrm{p}<0.01)$ and $43.2 \%$ financial difficulties (vs. $28.9 \%$ in 1972) $(p<0.05)$. The issue of the feelings and attitudes of the people towards the changes in the mode of life during 1990's is complicated. Some idea of this was given in one small study undertaken by the first author in Sofia in 1992-1993 with independent elderly people living active lives $[17,18]$. The study was directed on their feelings and attitudes way towards the life changes during the transition from totalitarianism towards democracy. The interviews with 61 elderly women and men (mean age 74 years), and the Self-evaluation test used, revealed a considerable variability of views confirming that old age is psychologically heterogeneous. Notwithstanding the richness of diverse views, $70 \%$ of the elderly could be polarized at the extremes: $35 \%$ showing a fully positive and optimistic attitude towards the changes and $35 \%$ definitely negative ones. The smallest groups had more mixed attitudes. The positive feelings of relief, joy, hope, were connected with ideas of liberation and freedom. The negative feelings of disappointment, pessimism and uncertainty implied worries about economic difficulties, delinquency, moral and cultural degradation, as well as fears of the restoration of communism, possible war and others dire consequences.

\section{Conclusion}

Two consecutive studies in 2007 and 2008 on the elderly from two Bulgarian villages revealed an unusually high prevalence of depression - surpassing $50 \%$ - in the age $60^{+}$. Depressive prevalence in Bulgaria proved to be much higher than it was in Romania at the same time on a similar rural population. The high prevalence in Bulgaria was confirmed by three scales of depression complemented by a Self-Evaluation Test (SET). The SET projects the self-esteem on the scales of 15 consecutively drawn vertical lines. The scores of the four instruments used are highly concordant, particularly related to the rates of moderate or severe depression which are around $40 \%$. The results indicate close relations between depression and Self-Evaluation (SE). The SET used is sensitive towards depressive symptoms; at the same time it has projective qualities giving information about personality values and motives of dissatisfaction.

The leading motives of personal dissatisfaction, including lower self-evaluation, according to the results of the 2008 study proved to be ill health and financial difficulties. In the 1970's study they were ill health, financial difficulties and problems in the family. The presence of depression may influence the self-evaluation regarding the ratings chosen. Conversely, the leading self-evaluation motives of personal dissatisfaction may help to understand better the psychosocial sources of depression. In that sense we are reminded of the statements of Martin Roth as well of Felix Post that $85 \%$ of late life depressions could be regarded as mostly psychogenic and/or somatogenic $[19,20]$. Depressive prevalence among Bulgarian rural elderly people in 2008 seemed to be higher and the self-evaluation of these people lower than it was in 1972. The rapid social and economic changes in Bulgaria after 1990 may contribute to some psychogenic increase of the number of depressive states.

\section{References}

1. Blazer DG (1993) Depression in late life (2ndedn). Mosby, Missouri, USA.

2. Blazer DG (1994) Epidemiology of late-life depression. In: Schneider LS, Reynolds CF, Lebowitz BD, Fried AJ (eds.). Diagnosis and treatment of depression in late life. American Psychiatric Press, Washington, DC, USA: 9-20.

3. Petrov IC (1983) Aging vs. depression. Nevrologiya, psihiatriya i nevrohirurgiya (Sofia) 22: 186-193.

4. Coleman PG, O'Hanlon A (2017) Aging and Development: Social and Emotional Perspectives. Routledge, Abingdon, UK.

5. Petrov IC (1976) Self-evaluation of some personality aspects of the aged by the test of Dembo-Rubinstein. Dissertation. Sofia, Medical academy, Bulgarian. 442.

6. Petrov IC (1976) Test of self-evaluation of personality and its social coherence. Nevrologiya, psihiatriya i nevrohirurgiya (Sofia) 15: 67-69.

7. Petrov IC (1997) A self-evaluation test in the early diagnostics of cognitive and affective disorders of elderly persons. In First Bologna International Meeting of Cognitive and Affective Disorders in the Elderly. Bologna, Casa Editrice Mattioli. 280-282.

8. Coleman PG, Carare RO, Petrov I, Forbes E, Saigal A, et al. (2011) Spiritual belief, social support, physical functioning and depression among older people in Bulgaria and Romania. Aging Ment Health 15: 327-323.

9. Zigmond AS, Snaith RP (1983) The hospital anxiety and depression scale. Acta Psychiatr Scand 67: 361-370.

10. Zung WW (1965) A self-rating depression scale. Arch Gen Psychiatry 12: 63-70.

11. Yesavage JA, Brink TL, Rose TL, Lum O, Huang V, et al. (1983) Development and validation of a geriatric depression screening scale: A preliminary report. J Psychiatr Res 17: 37-49.

12. Coleman PG (2011) Belief and Ageing: Spiritual pathways in later life. Policy Press, England, UK. 
Citation: Petrov IC, Coleman PG (2019) Aging and Depression: Studies on Rural Populations in Bulgaria during Communist and Post Communist Period. J Gerontol Geriatr Med 5: 037.

13. Petrov IC (2000) Mental health of the rural elderly. A study of a representative sample of Bulgarian Shopp population. Cross-sectional data. In Second Bologna Meeting on Cognitive, Affective and Behavior Disorders in the Elderly, June 2000. Abstract Book. Bologna, Italy. 153-154.

14. Petrov IC (2009) Mental health of the rural elderly population: Focus on depressions. XIX World Congress of Gerontology and Geriatrics, Paris.

15. Petrov IC (1981) Etats depressifs apres l'age de soixante-dix ans. Etude clinique et experimentale sur un groupe homogene de 701 habitants ruraux. Minerva medica 72: 3191-3195.

16. Petrov IC, Coleman PG (2011) The high rates of depressions among older Bulgarian rural people: Is there a real depression or a pessimistic self-evaluation? Aging Clinical and experimental research 23: 268.
17. Petrov I C (1996) Feelings and attitudes toward the changes during social and economic transition. A study of Sofia autonomous elderly subjects. Romanian Journal of Gerontology 17: 73-82.

18. Petrov IC (2007) The elderly in a period of transition: health, personality, and social aspects of adaptation. Ann N Y Acad Sci 1114: 300-309.

19. Roth M (1965) Late depressions. In: Davies EB (ed.). Depression. A Cambridge post-graduate medical course. Cambridge University Press, Cambridge, UK.

20. Post F (1972) The Management and Nature of Depressive Illnesses in Late Life: A Follow-Through Study. The British Journal of Psychiatry 121: 393404. 


\section{II}

Journal of Anesthesia \& Clinical Care

Journal of Addiction \& Addictive Disorders

Advances in Microbiology Research

Advances in Industrial Biotechnology

Journal of Agronomy \& Agricultural Science

Journal of AIDS Clinical Research \& STDs

Journal of Alcoholism, Drug Abuse \& Substance Dependence

Journal of Allergy Disorders \& Therapy

Journal of Alternative, Complementary \& Integrative Medicine

Journal of Alzheimer's \& Neurodegenerative Diseases

Journal of Angiology \& Vascular Surgery

Journal of Animal Research \& Veterinary Science

Archives of Zoological Studies

Archives of Urology

Journal of Atmospheric \& Earth-Sciences

Journal of Aquaculture \& Fisheries

Journal of Biotech Research \& Biochemistry

Journal of Brain \& Neuroscience Research

Journal of Cancer Biology \& Treatment

Journal of Cardiology: Study \& Research

Journal of Cell Biology \& Cell Metabolism

Journal of Clinical Dermatology \& Therapy

Journal of Clinical Immunology \& Immunotherapy

Journal of Clinical Studies \& Medical Case Reports

Journal of Community Medicine \& Public Health Care

Current Trends: Medical \& Biological Engineering

Journal of Cytology \& Tissue Biology

Journal of Dentistry: Oral Health \& Cosmesis

Journal of Diabetes \& Metabolic Disorders

Journal of Dairy Research \& Technology

Journal of Emergency Medicine Trauma \& Surgical Care

Journal of Environmental Science: Current Research

Journal of Food Science \& Nutrition

Journal of Forensic, Legal \& Investigative Sciences

Journal of Gastroenterology \& Hepatology Research

Journal of Gerontology \& Geriatric Medicine

Journal of Genetics \& Genomic Sciences

Journal of Hematology, Blood Transfusion \& Disorders

Journal of Human Endocrinology

Journal of Hospice \& Palliative Medical Care

Journal of Internal Medicine \& Primary Healthcare

Journal of Infectious \& Non Infectious Diseases

Journal of Light \& Laser: Current Trends

Journal of Modern Chemical Sciences

Journal of Medicine: Study \& Research

Journal of Nanotechnology: Nanomedicine \& Nanobiotechnology

Journal of Neonatology \& Clinical Pediatrics

Journal of Nephrology \& Renal Therapy

Journal of Non Invasive Vascular Investigation

Journal of Nuclear Medicine, Radiology \& Radiation Therapy

Journal of Obesity \& Weight Loss

Journal of Orthopedic Research \& Physiotherapy

Journal of Otolaryngology, Head \& Neck Surgery

Journal of Protein Research \& Bioinformatics

Journal of Pathology Clinical \& Medical Research

Journal of Pharmacology, Pharmaceutics \& Pharmacovigilance

Journal of Physical Medicine, Rehabilitation \& Disabilities

Journal of Plant Science: Current Research

Journal of Psychiatry, Depression \& Anxiety

Journal of Pulmonary Medicine \& Respiratory Research

Journal of Practical \& Professional Nursing

Journal of Reproductive Medicine, Gynaecology \& Obstetrics

Journal of Stem Cells Research, Development \& Therapy

Journal of Surgery: Current Trends \& Innovations

Journal of Toxicology: Current Research

Journal of Translational Science and Research

Trends in Anatomy \& Physiology

Journal of Vaccines Research \& Vaccination

Journal of Virology \& Antivirals

Archives of Surgery and Surgical Education

Sports Medicine and Injury Care Journal

International Journal of Case Reports and Therapeutic Studies

Journal of Ecology Research and Conservation Biology

Submit Your Manuscript: http://www.heraldopenaccess.us/Online-Submission.php 